\title{
Loop Heat Pipe Transient Behavior Using Heat Source Temperature for Set Point Control with Thermoelectric Converter on Reservoir
}

\author{
Jentung $\mathrm{Ku}^{1}$ \\ NASA Goddard Space Flight Center Greenbelt, Greenbelt, Maryland, USA, 20771 \\ Kleber Paiva ${ }^{2}$ \\ Marcia Mantelli ${ }^{3}$ \\ Federal University of Santa Catarina, Florianópolis, Santa Catarina, Brazil, 88040-900
}

\begin{abstract}
The LHP operating temperature is governed by the saturation temperature of its reservoir. Controlling the reservoir saturation temperature is commonly done by cold biasing the reservoir and using electrical heaters to provide the required control power. With this method, the loop operating temperature can be controlled within $\pm 0.5 \mathrm{~K}$ or better. However, because the thermal resistance that exists between the heat source and the LHP evaporator, the heat source temperature will vary with its heat output even if the LHP operating temperature is kept constant. Since maintaining a constant heat source temperature is of most interest, a question often raised is whether the heat source temperature can be used for LHP set point temperature control. A test program with a miniature LHP was carried out to investigate the effects on the LHP operation when the control temperature sensor was placed on the heat source instead of the reservoir. In these tests, the LHP reservoir was cold-biased and was heated by a control heater. Test results show that it was feasible to use the heat source temperature for feedback control of the LHP operation. In particular, when a thermoelectric converter was used as the reservoir control heater, the heat source temperature could be maintained within a tight range using a proportional-integral-derivative or on/off control algorithm. Moreover, because the TEC could provide both heating and cooling to the reservoir, temperature oscillations during fast transients such as loop startup could be eliminated or substantially reduced when compared to using an electrical heater as the control heater.
\end{abstract}

\section{Nomenclature/Acronym/Symbol}

$\begin{array}{ll}\mathrm{CC} & =\text { compensation chamber } \\ \mathrm{EH} & =\text { electrical heater } \\ \text { EVAP } & =\text { evaporator } \\ \text { LHP } & =\text { loop heat pipe } \\ \text { PID } & =\text { proportional-integral-derivative } \\ \mathrm{TEC} & =\text { thermoelectric converter } \\ \mathrm{TM} & =\text { thermal mass }\end{array}$

\footnotetext{
${ }^{1}$ Laboratory Manager, Thermal Engineering Branch, Goddard Space Flight Center, Greenbelt, Maryland, USA, AIAA Senior Member.

${ }^{2}$ NASA Visitng Researcher; Ph.D. Candidate, Department of Mechanical Engineering, Federal University of Santa Catarina, Florianópolis, Santa Catarina, Brazil.

${ }^{3}$ Professor, Department of Mechanical Engineering, Federal University of Santa Catarina, Florianópolis, Santa Catarina, Brazil.
} 


\section{Introduction}

A LOOP heat pipe (LHP) is a very robust and versatile heat transfer device which can transport large heat loads over long distances with small temperature differences ${ }^{1,2}$. It utilizes boiling and condensation to transfer heat, and the surface tension force developed at the liquid/vapor interface on the evaporator wick to sustain the flow circulation. LHPs are being used on several commercial communications satellites and NASA's Swift, Aura, GOES$\mathrm{N}$ and GOES-R spacecraft ${ }^{3-11}$. The LHP operating temperature is governed by the saturation temperature of its reservoir (also called the compensation chamber); the latter is a function of the heat load to the evaporator and the condenser sink temperature. For spacecraft applications requiring a narrow temperature range, regulating the LHP operating temperature becomes necessary. There are various ways to control the LHP operating temperature, depending upon the requirement on the tightness of the temperature control and the availability of the spacecraft power ${ }^{12-13}$. Nevertheless, all temperature control methods use the same underlying principal, i.e. to cold bias the LHP reservoir and use a control heater to maintain the reservoir temperature at the desired set point. In all of the LHPs onboard the above-mentioned orbiting spacecraft, the temperature sensor used for LHP operating temperature control has been placed on the reservoir. Using this method, the loop operating temperature can be controlled within $\pm 0.5 \mathrm{~K}$ or better. However, because of the thermal resistance that exists between the heat source and the LHP evaporator, the heat source temperature will vary with its heat output even if the LHP operating temperature is maintained constant. Since maintaining a constant heat source temperature is of most interest to the users, a question often raised is whether the heat source temperature can be used for LHP set point control.

A test program with an LHP was carried out to investigate the effects on the LHP operation when the control temperature sensor was placed on the heat source instead of the reservoir. The test article is a miniature LHP made by the Thermacore, Inc. in 2003. The loop was tested for its heat transport performance in 2003 under a laboratory condition and demonstrated a heat transport capability of $140 \mathrm{~W}^{14}$. The loop was dormant between 2003 and 2009. Tests under the current program were conducted between December 2009 and February 2010, and between April and June 2011. In these tests, a thermal mass (TM) that simulated the heat source was attached to the LHP evaporator, and the LHP reservoir was cold-biased and heated by a control heater. In addition to the location of the control temperature sensor, other test variables included: 1) thermal mass of 117 grams and 350 grams; 2) heat load to the thermal mass between $10 \mathrm{~W}$ and $140 \mathrm{~W}$; 3) electrical heater (EH) versus thermoelectric converter (TEC) attached to the reservoir to serve as the control heater; and 4) proportional-integral-derivative (PID) versus on/off control scheme for the reservoir control heater.

This paper presents some of the test results when a TEC was attached to the reservoir as the control heater. Both the PID and the on/off control schemes were tested. In the following descriptions, the terms reservoir and compensation chamber (CC) are used interchangeably.

\section{Test Article and Test Setup}

The test article was a miniature LHP which consisted of an evaporator with an integral CC, a vapor line, a liquid line and a condenser ${ }^{14}$. Main features of this miniature LHP included: 1) a 7-mm O.D. evaporator, 2) a stainless steel (SS) primary wick with $1.2 \mu \mathrm{m}$ pore size, 3) SS vapor and liquid transport lines with a $1.59 \mathrm{~mm}$ O.D., 4) an aluminum condenser with a $2.39 \mathrm{~mm}$ O.D., and 5) a fluid inventory of 1.5 gram of ammonia. Main design parameters are summarized in Table 1. Figure 1 shows a picture of the test article when it was delivered in 2003 where, for clarity, a portion of the transport lines has been left out. Figure 2 shows a close-up view of the evaporator and CC. A TEC was attached to the CC and a copper strap connected the hot side of the TEC to the evaporator. The condenser was serpentined for four passes and was mounted to an aluminum cold plate as shown in Table 1. Summary of Design Parameters

\begin{tabular}{|l|l|}
\hline \multicolumn{1}{|c|}{ Item } & \multicolumn{1}{c|}{ Description } \\
\hline Evaporator & Aluminum Shell, $7 \mathrm{~mm}$ O.D. $\times 51 \mathrm{~mm} \mathrm{~L}$ \\
\hline Primary Wick & SS, $5.6 \mathrm{~mm}$ O.D. $\times 2.4 \mathrm{~mm}$ I.D \\
& $1.2 \mu \mathrm{m}$ pore size, $1.0 \times 10^{-14} \mathrm{~m}^{2}$ permeability \\
\hline Secondary Wick & SS screen, $400 \times 400$ mesh \\
\hline Compensation Chamber & SS, $9.52 \mathrm{~mm}$ O.D. $\times 25.5 \mathrm{~mm} \mathrm{~L}$ \\
\hline Vapor Line & SS, $1.59 \mathrm{~mm}$ O.D. $\times 560 \mathrm{~mm} \mathrm{~L}$ \\
\hline Liquid Line & SS, $1.59 \mathrm{~mm}$ O.D. $\times 635 \mathrm{~mm} \mathrm{~L}$ \\
\hline Condenser & Aluminum, $2.39 \mathrm{~mm}$ O.D. $\times 200 \mathrm{mmL}$ \\
\hline Working Fluid & Ammonia, 1.5 grams \\
\hline Total Mass & 79 grams \\
\hline
\end{tabular}
Figure 3. 
In this test program, a Dale Ohm electrical heater was attached to the reservoir while keeping the original TEC. In addition, two aluminum thermal masses, 117 grams and 350 grams (the combination of 117gram and 233-gram masses) shown in Figure 4, were attached to the aluminum saddle. Each of the two aluminum masses (117 grams and 233 grams) contained holes to accommodate cartridge heaters which provided up to $150 \mathrm{~W}$ of power. The thermal mass served as the instrument simulator (the heat source) which dissipated heat to the LHP. The condenser plate was cooled by a refrigerator by flowing coolant to the copper tube soldered to the plate (Figure
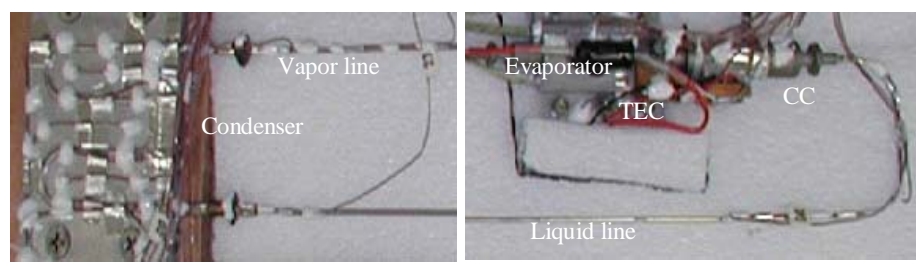

Figure 1. Picture of the Miniature LHP

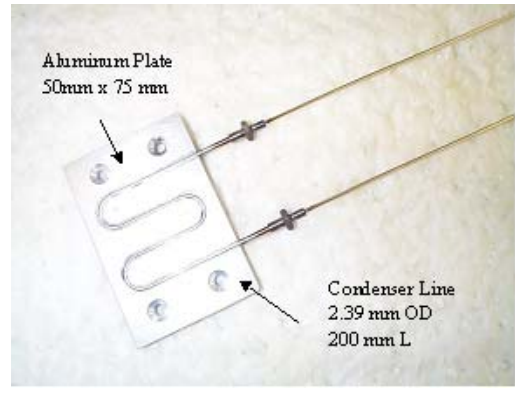

Figure 3. Picture of the Condenser Section

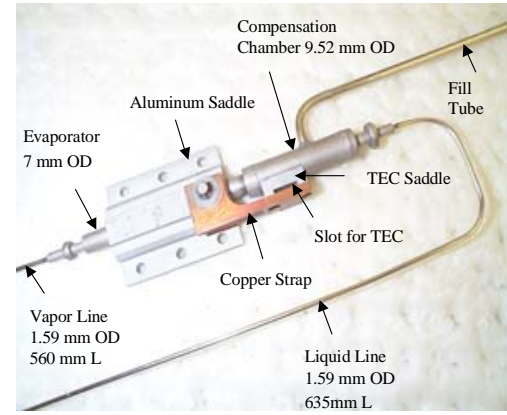

Figure 2. Picture of the Evaporator and CC Section 5).

The reservoir was cold biased by the cold liquid returning from the condenser, and was heated either by the electrical heater or the TEC. A bipolar power supply was used for TEC operation. By changing the polarity of the power supply, the TEC could heat or cool the reservoir. The TEC power was calculated from the measured voltage and current, where positive and negative voltages indicated that the reservoir was being heated and cooled, respectively. Thermostats were used for all heaters for over temperature protection. A Labview program was used to regulate the reservoir temperature by using either the PID or on/off control scheme. The parameters for the PID control were fixed for all tests. A dead band of $0.1 \mathrm{~K}$ was used when the on/off control scheme was employed.

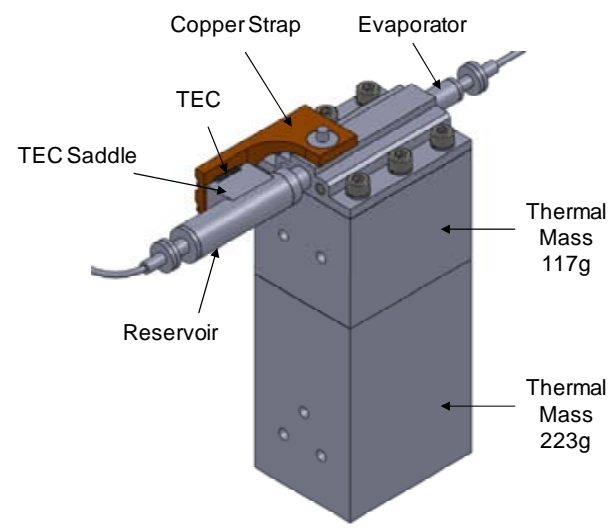

Figure 4. Evaporator/CC Thermal Masses

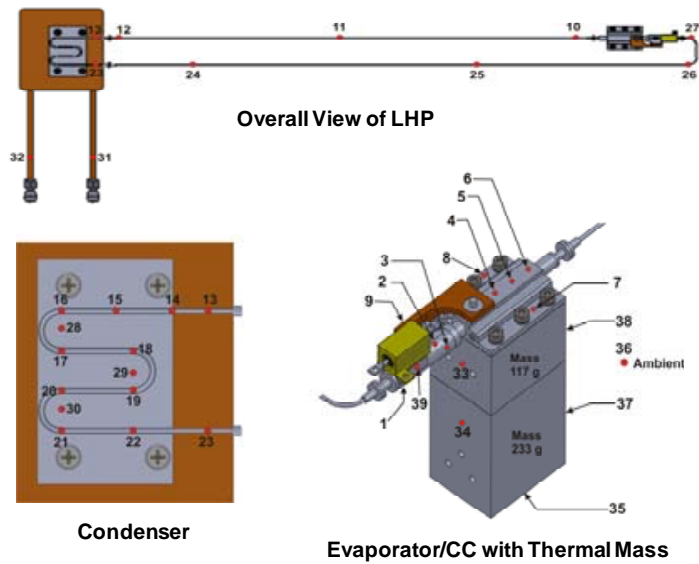

Figure 5. Thermocouple Locations

Forty type T thermocouples were used to monitor the temperatures of the LHP components and the test setup as shown in Figure 5. Tests were conducted by using thermocouples (TCs) \#2, \#5, and \#33 for set point temperature control of the reservoir, evaporator and thermal mass, respectively. A data acquisition system consisting of a personal computer, a CRT monitor, an HP data logger, and Labview software was used to display and store data every two seconds. 


\section{Test Program}

The main objective of this test program was to investigate the feasibility of operating the LHP when the control temperature sensor was placed on the heat source. The LHP operating temperature was still governed by the temperature of its reservoir, and the latter was cold biased and heated by a control heater. In this test program the control temperature sensor was placed on the reservoir, evaporator, and thermal mass (simulating the heat source) to maintain the respective component at a constant temperature. Placing the control temperature sensor on the reservoir represents the traditional way of operating the LHP. The thermal mass was installed in such a way as to create a relatively large thermal resistance for heat conduction $(0.23 \mathrm{~K} / \mathrm{W})$ between the thermal mass and the LHP evaporator. In contrast, placing the control temperature sensor on the evaporator represents the condition of nearzero thermal resistance between the thermal mass and the LHP.

Other variables in this test program included: 1) thermal mass of 117 grams and 350 grams; 2) heat load to the thermal mass between $10 \mathrm{~W}$ and $140 \mathrm{~W}$; 3) electrical heater versus TEC attached to the reservoir as the control heater; and 4) proportional-integralderivative versus on/off control scheme for the reservoir control heater. The test variables are illustrated in Figure 6.

Each test was conducted by selecting the thermal mass to be attached, the reservoir control heater, the temperature control scheme, and the location of the control temperature sensor. The set point temperature

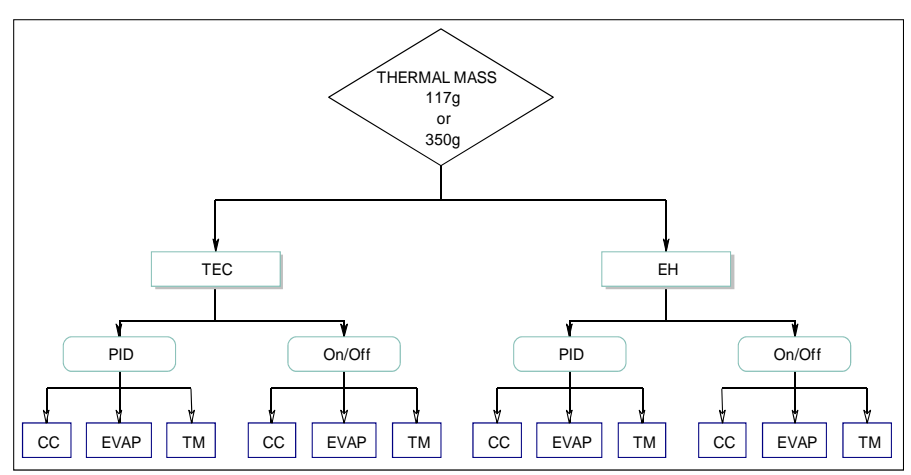

Figure 6. Diagram of Overall Test Program was fixed at 293K, 303K, and 313K when the control temperature sensor was placed on the reservoir, evaporator and thermal mass, respectively. Power was then applied to the thermal mass, and increased in steps after a steady state was reached at each step. Once the thermal mass temperature exceeded $343 \mathrm{~K}$ or the condenser exhausted its convective heat dissipating capability, the power was lowered to $30 \mathrm{~W}$ and $10 \mathrm{~W}$. Using different set point temperatures when the control temperature sensor was placed on different components allowed the LHP to operate over a similar power range for all tests.

\section{Test Results}

Extensive power ramp-up tests shown in Figure 6 have been conducted. In addition, several power cycle tests were performed where the control temperature sensor was placed on the thermal mass with a set point of 313K and on the reservoir with a set point of $298 \mathrm{~K}$. The heat load to the thermal mass was cycled between $20 \mathrm{~W}$ and $80 \mathrm{~W}$ and between $40 \mathrm{~W}$ and $80 \mathrm{~W}$ for several hours. The following discussions focus on tests with TEC attached to the LHP reservoir as the control heater although some tests with electrical heater attached to the reservoir will also be presented for comparison. TECs have been used on several LHPs, including an LHP with two evaporators and two condensers, to control the CC temperature in ground tests and demonstrated excellent performance ${ }^{14-17}$. The TEC has an advantage over the traditional electrical heater in that a single device can provide both heating and cooling to the reservoir. Using a bipolar power supply, the TEC can automatically switch its operation between the heating and cooling modes as required. Tests were conducted with PID and on/off control schemes, and with 117-gram and 350gram thermal masses. The presentations below are arranged in groups so as to illustrate the effects on the LHP operation due to: 1) the heat load to the thermal mass; 2) the location of the control temperature sensor; 3) the use of the PID and on/off control schemes, 4) the thermal mass, and 5) the power cycle.

Each test was performed as follows. Prior to the LHP startup, the condenser sink was cooled to $253 \mathrm{~K}$. As soon as the heat load was applied to the thermal mass, control of the set point temperature for the designated component (the reservoir, evaporator, or thermal mass) was activated. After the LHP successfully started and the designated component for temperature control reached a steady state, the heat load to the thermal mass was increased in steps until the thermal mass temperature exceeded $343 \mathrm{~K}$ or the condenser exhausted its convective heat dissipating capability. Afterwards, the heat load was reduced to $30 \mathrm{~W}$ and $10 \mathrm{~W}$ to demonstrate that the LHP could resume its normal temperature control function. The power cycle test was conducted by cycling the heat load to the thermal mass between $20 \mathrm{~W}$ and $80 \mathrm{~W}$ and between $40 \mathrm{~W}$ and $80 \mathrm{~W}$. In the following figures, selected thermocouples (TCs) 
were used to illustrate temperatures of the various elements: TC 2 - CC, TC 5 - evaporator, TC 11 - vapor line, TC 24 - liquid line, TC 27 - liquid line at the CC inlet, and TC 34 - thermal mass.

117-gram Thermal Mass and PID Control Scheme - The first group of tests had the 117-gram thermal mass attached to the evaporator and the PID control scheme was employed. Figure 7 shows the temperature profiles for the test where the control temperature sensor (TC \#2) was placed on the reservoir with a set point of 293K. Initially, the reservoir was pre-heated to $298 \mathrm{~K}$ so as to flood the entire loop with ammonia. A heat load of $10 \mathrm{~W}$ was then applied to the thermal mass for startup, and the PID control scheme was activated to maintain the reservoir at 293K. Details of the startup transient will be discussed in the next section. After the loop started, the TEC was able to maintain the reservoir temperature at the $293 \mathrm{~K}$ set point for heat loads between $10 \mathrm{~W}$ and $120 \mathrm{~W}$. At each power increase, the evaporator and thermal mass rose to higher temperatures due to the heat transfer requirement. At $140 \mathrm{~W}$, the condenser exceeded its heat dissipating capability at a vapor temperature of $293 \mathrm{~K}$. Warm liquid returned to the reservoir, raising the reservoir temperature to $297 \mathrm{~K}$, which was its natural operating temperature at thermal equilibrium. Because the reservoir temperature was above its set point of $293 \mathrm{~K}$, the TEC operated in the cooling mode, attempting to maintain the reservoir set point temperature. When the heat load was reduced to $30 \mathrm{~W}$ and $10 \mathrm{~W}$, the TEC was able to maintain the reservoir at the $293 \mathrm{~K}$ set point again, and the evaporator and thermal mass temperatures dropped accordingly.

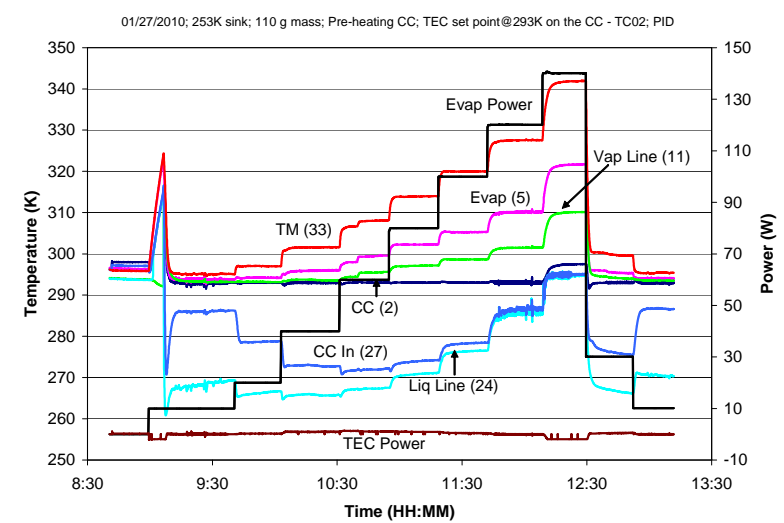

Figure 7. Temperature Profiles for Test with Reservoir Controlled at 293K (117g/TEC/PID)

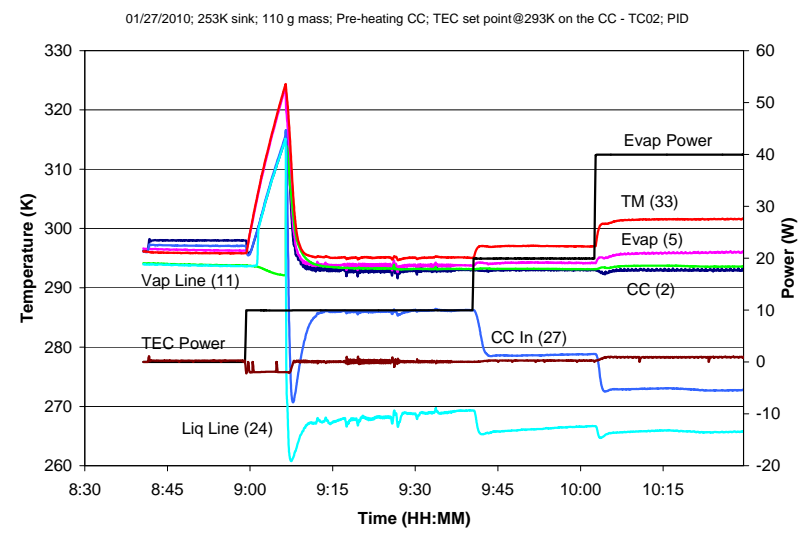

Figure 8. Temperature Profiles for Startup with Reservoir Controlled at 293K (117g/TEC/PID)

Figure 8 shows details of the startup transient. Prior to the inception of the startup, the evaporator and thermal mass were at the room temperature of $294 \mathrm{~K}$. Because the reservoir had already been heated to 298K, the TEC was operating in the cooling mode to cool the reservoir as indicated by the negative TEC power. The thermal mass and evaporator were gradually heated by the $10 \mathrm{~W}$ heat load to temperatures higher than that of the reservoir. Because of the heat leak from the evaporator to the reservoir, the TEC with $2 \mathrm{~W}$ power was unable to cool the reservoir to $293 \mathrm{~K}$. During this period, a back flow of the working fluid occurred in the LHP as indicated by the rise of the liquid line temperature and the fall of the vapor line temperature. When the loop finally started, a forward flow was established as evidenced by the rise of the vapor line temperature and the fall of the liquid line temperature. Subsequently, cold liquid flowed from the condenser to the reservoir, and the TEC heated the reservoir to maintain the reservoir at its set point temperature of $293 \mathrm{~K}$. Because of the thermal resistances, the evaporator and the thermal mass were at higher temperatures than the reservoir. After the loop reached a steady state, the heat load was increased to 20W.

Figure 9 show the temperature profiles for a test similar to that of Figure 7, except that the control temperature sensor was placed on the evaporator (TC \#5) with a set point temperature of 303K. In this case, the TEC was able to maintain the evaporator temperature at 303K for heat loads between $10 \mathrm{~W}$ and $100 \mathrm{~W}$. As the heat load increased, the thermal mass temperature increased because a higher temperature difference was needed to transfer a higher power. Likewise, the reservoir temperature decreased with an increasing heat load in order to keep the evaporator temperature constant. At $100 \mathrm{~W}$, the reservoir temperature was $291 \mathrm{~K}$. At $120 \mathrm{~W}$, the reservoir temperature rose to 293K in order to dissipate the higher power. Consequently, the evaporator temperature rose above its set point temperature. The TEC was commanded to turn on and drew the maximum available control power of $2 \mathrm{~W}$, attempting to cool the reservoir and maintain the evaporator set point temperature. When the heat load was decreased to $30 \mathrm{~W}$ and then $10 \mathrm{~W}$, the condenser resumed its heat dissipating capability at a lower reservoir temperature and the evaporator was again controlled at 303K. 
Figure 10 shows the temperature profiles during the startup transient. Initially, the reservoir was heated to $298 \mathrm{~K}$ for pre-conditioning. The evaporator and thermal mass were at $295 \mathrm{~K}$. As a heat load of $10 \mathrm{~W}$ was applied, the command to control the evaporator at $303 \mathrm{~K}$ was activated. Because the evaporator was below its set point of 303K, the TEC began to heat the reservoir. With $10 \mathrm{~W}$ to the thermal mass, the evaporator was also heated and its temperature gradually rose. When the evaporator temperature exceeded 303K, the TEC switched to the cooling mode and the reservoir temperature began to drop. Soon after, the reservoir temperature dropped below the evaporator temperature by about $3 \mathrm{~K}$ and the loop started. With cold liquid returning from the condenser to the reservoir, the TEC switched to the heating mode to maintain the evaporator set point temperature at $303 \mathrm{~K}$.

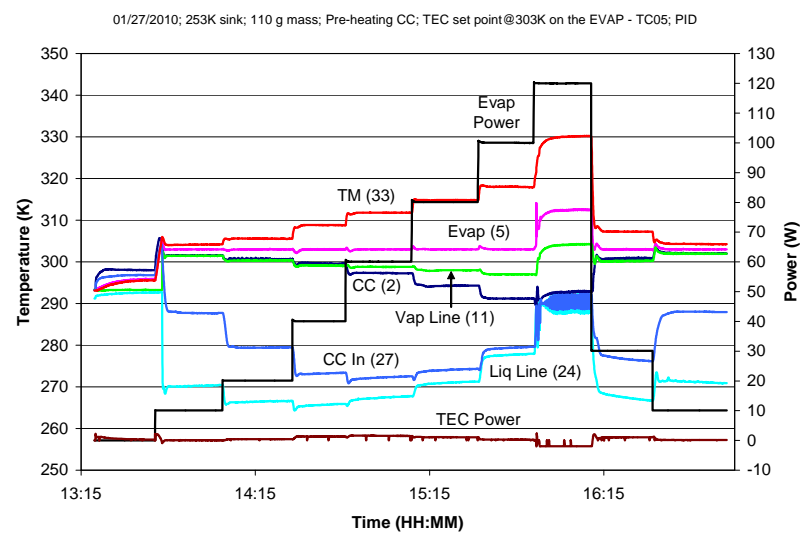

Figure 9. Temperature Profiles for Test with Evaporator Controlled at 303K (117g/TEC/PID)

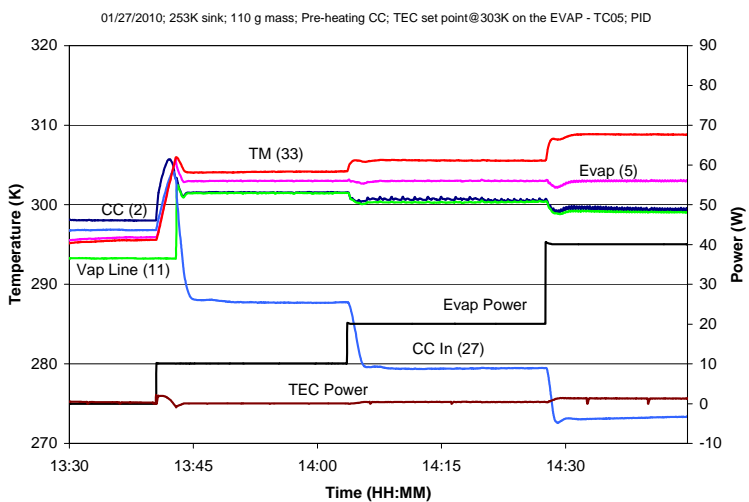

Figure 10. Temperature Profiles for Startup with Evaporator Controlled at 303K (117g/TEC/PID)

The temperature profiles for the test with the control temperature sensor placed on the thermal mass (TC\#33) are shown in Figure 11. The goal was to maintain the thermal mass (the heat source) at a constant temperature under various heat loads. For the heat loads of $10 \mathrm{~W}$, large temperature oscillations were observed and the thermal mass could not be kept at its set point temperature of 313K. In fact, the loop underwent repeated startup and shutdown cycles. Only when the heat load was increased to $20 \mathrm{~W}$ or higher was the thermal mass temperature maintained at 313K without temperature oscillations. At each power increase, the reservoir temperature was automatically lowered in order to maintain the thermal mass at $313 \mathrm{~K}$. At $100 \mathrm{~W}$, the reservoir temperature could only be lowered to $288 \mathrm{~K}$, the loop's natural operating temperature under this condition, which was not low enough to keep the thermal mass at $313 \mathrm{~K}$. When the heat load was decreased to $30 \mathrm{~W}$, the reservoir temperature dropped and the thermal mass was kept at $313 \mathrm{~K}$ again. As the heat load was lowered to $10 \mathrm{~W}$, large temperature oscillations reappeared. These temperature oscillations at low heat loads were a result of interactions among the control heater, reservoir and thermal mass, as will be explained next.

The transient phenomena for loop startup with low powers are illustrated in Figure 12. Initially, the evaporator, and thermal mass were at $295 \mathrm{~K}$. The reservoir was heated to $298 \mathrm{~K}$. As a heat load of $10 \mathrm{~W}$ was applied to the

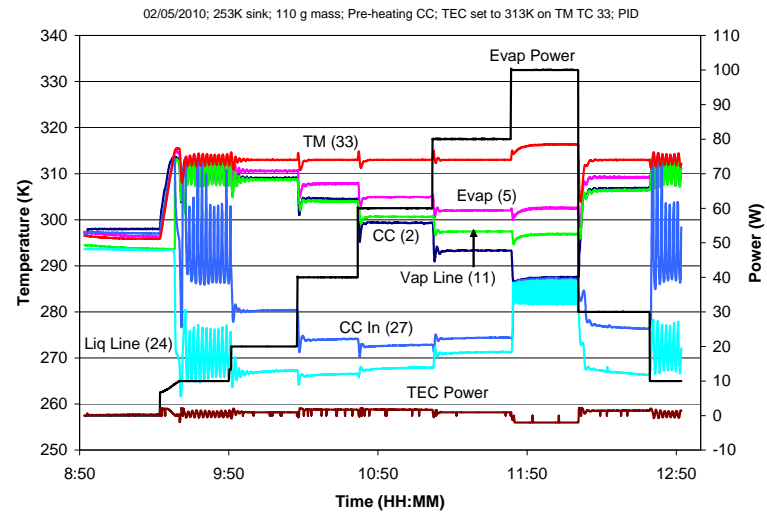

Figure 11. Temperature Profiles for Test with Thermal Mass Controlled at 313K (117g/TEC/PID)

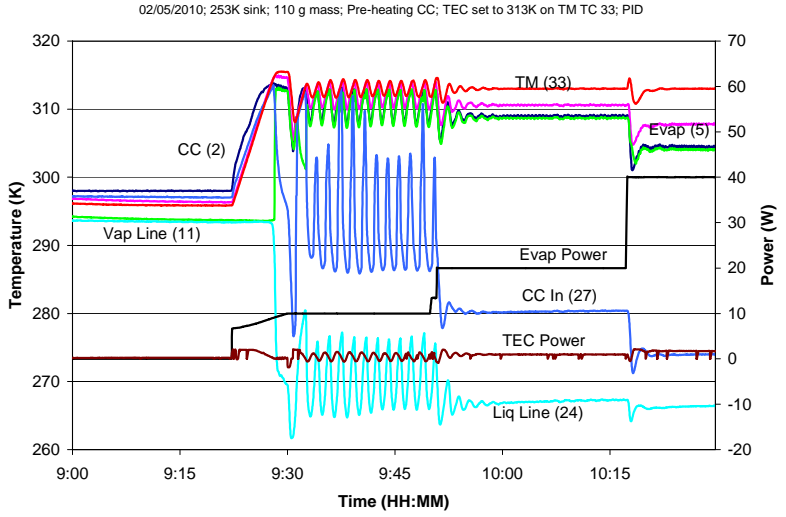

Figure 12. Temperature Profiles for Startup with Thermal Mass Controlled at 313K (117g/TEC/PID)

6

American Institute of Aeronautics and Astronautics 
thermal mass, the reservoir heater control was activated and the TEC was turned on to maintain the thermal mass at $313 \mathrm{~K}$. With $2 \mathrm{~W}$ to the reservoir and $10 \mathrm{~W}$ to the 117 -gram thermal mass, the reservoir temperature rose at a faster rate than the thermal mass and evaporator. When the thermal mass temperature exceeded 313K, the TEC switched to the cooling mode, resulting in a decrease of the reservoir temperature. The thermal mass temperature continued to rise while the reservoir temperature was decreasing. The loop started when the temperature differential between the evaporator and the reservoir reached about $2 \mathrm{~K}$ (the wall superheat). With the injection of cold liquid from the condenser to the reservoir immediately following the startup, the reservoir temperature dropped sharply and so did the thermal mass. When the thermal mass temperature dropped below 313K, the TEC began to heat the reservoir. The reservoir temperature again rose at a faster rate than that of the thermal mass. The loop was subsequently shut down. What followed were repeated startup and shutdown cycles. When the heat load was increased to 20W, the rate of temperature increase in the reservoir no longer exceeded that of the thermal mass. Consequently, there were no repeated startup and shutdown cycles and the loop ran steadily with the thermal mass maintained at 313K.

117-gram Thermal Mass and PID Control Scheme - The above-mentioned tests were repeated with the TEC controlled by an on/off scheme. Figure 13 shows the temperature profiles where the control temperature sensor was placed on the reservoir with a set point of 293K. These temperature profiles are similar to those shown in Figure 7 in that the reservoir temperature was kept constant for all the heat loads until the condenser ran out of its heat dissipating capability, that the evaporator and the thermal mass temperatures rose with each power increase, and that the reservoir resumed its temperature control function after the heat load was reduced to $30 \mathrm{~W}$ and $10 \mathrm{~W}$ near the end of the test. However, temperatures of the reservoir, evaporator, and thermal mass showed larger oscillations than those shown in Figure 7. This difference was the result of using the on/off control scheme instead of the PID scheme. It was observed during the test that the rise and fall of the temperatures of the reservoir, evaporator, and thermal mass corresponded to the on and off cycles of the TEC power. The transient behavior illustrated by Figure 14 was somewhat different from that illustrated by Figure 8. The loop started shortly after 10W was applied to the thermal mass. The required superheat for startup was much smaller than that shown in Figure 8. The superheat requirement for start-up is stochastic in nature and cannot be predicted. The loop simply displayed two different superheats at the boiling inception in these tests.

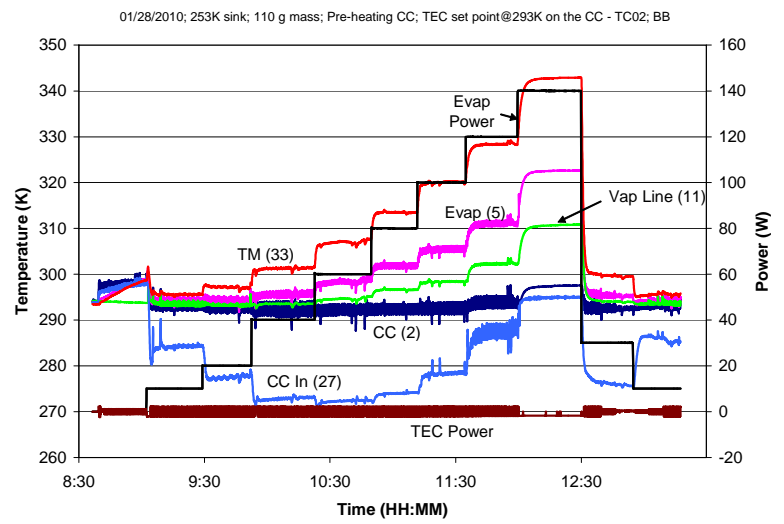

Figure 13. Temperature Profiles for Test with Reservoir Controlled at 293K (117g/TEC/on-off)

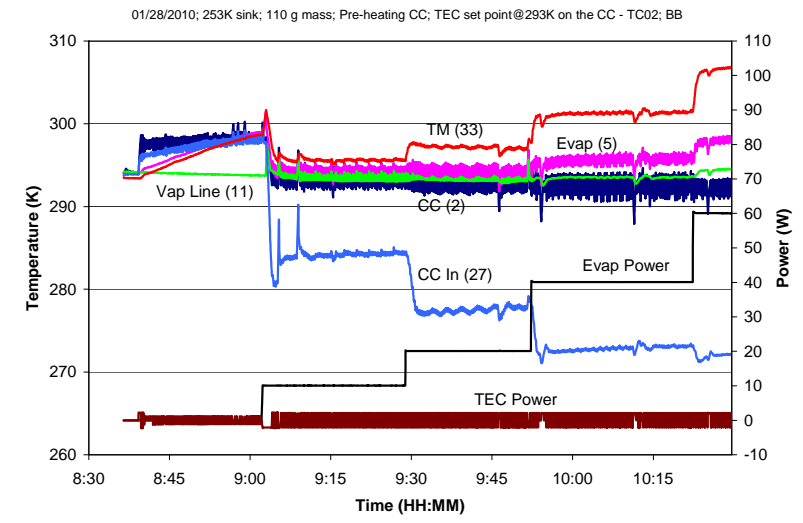

Figure 14. Temperature Profiles for Startup with Reservoir Controlled at 293K (117g/TEC/on-off)

Figure 15 shows the temperature profiles for the test with the control temperature sensor located on the evaporator and set at 303K. They are similar to those shown in Figure 9 except that amplitudes of temperature oscillations for the reservoir, evaporator and thermal mass were larger than those when the PID control scheme was employed. At $120 \mathrm{~W}$, the condenser reached its heat dissipating capability. The loop operated at the reservoir's natural operating temperature of $292 \mathrm{~K}$ and the evaporator temperature rose to $310 \mathrm{~K}$, higher than its set point of 303K. The startup transient was illustrated in Figure 16. When a heat load of 10W was applied to the thermal mass, the TEC heated the reservoir until the evaporator reached 303K. The TEC was then switched to the cooling mode and the loop started with a small superheat. Again, the rise and fall of temperatures of the reservoir, evaporator, and thermal mass corresponded to the on and off cycles of the TEC power. 


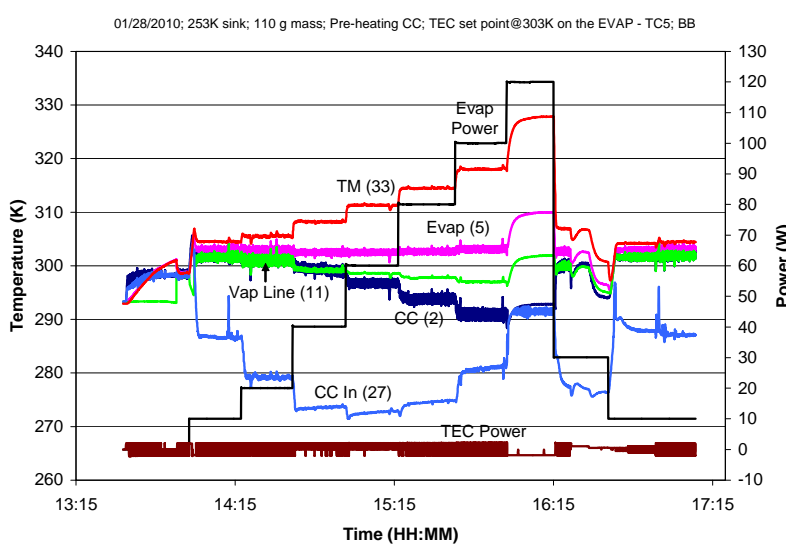

Figure 15. Temperature Profiles for Test with Evaporator Controlled at 303K (117g/TEC/on-off)

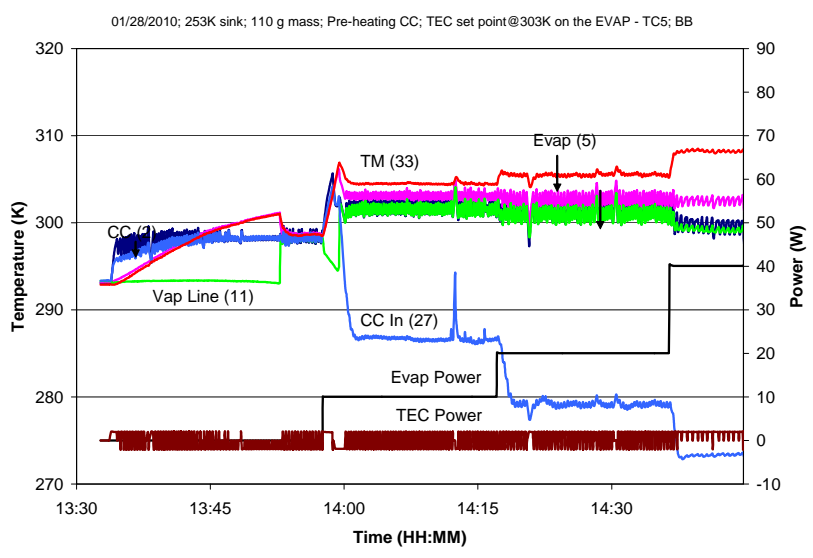

Figure 16. Temperature Profiles for Startup with Evaporator Controlled at 303K (117g/TEC/on-off)

Temperature profiles for the LHP operation with the control temperature sensor placed on the thermal mass and controlled at $313 \mathrm{~K}$ are shown in Figure 17. With $10 \mathrm{~W}$ to the thermal mass, the loop displayed repeated startup and shutdown cycles as shown more detailed in Figure 18. The loop started at 20W although small temperature oscillations persisted. Temperatures were stable and the thermal mass temperature was maintained at 313K over the power range between $40 \mathrm{~W}$ and $80 \mathrm{~W}$. In this power range, temperature fluctuations were mainly due to the on/off cycles of the TEC control. At $100 \mathrm{~W}$ and $120 \mathrm{~W}$, the reservoir was at its natural equilibrium temperatures, which were not low enough to maintain the thermal mass at its set point temperature of $313 \mathrm{~K}$.

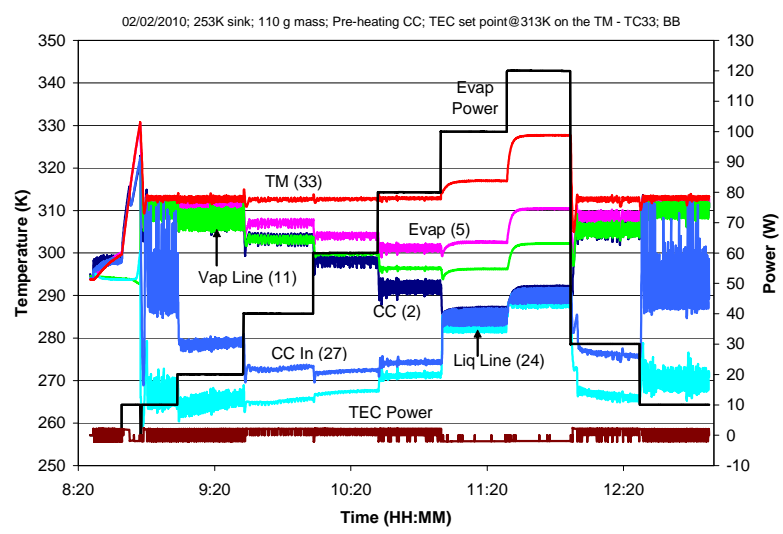

Figure 17. Temperature Profiles for Test with Thermal Mass Controlled at 313K (117g/TEC/on-off)

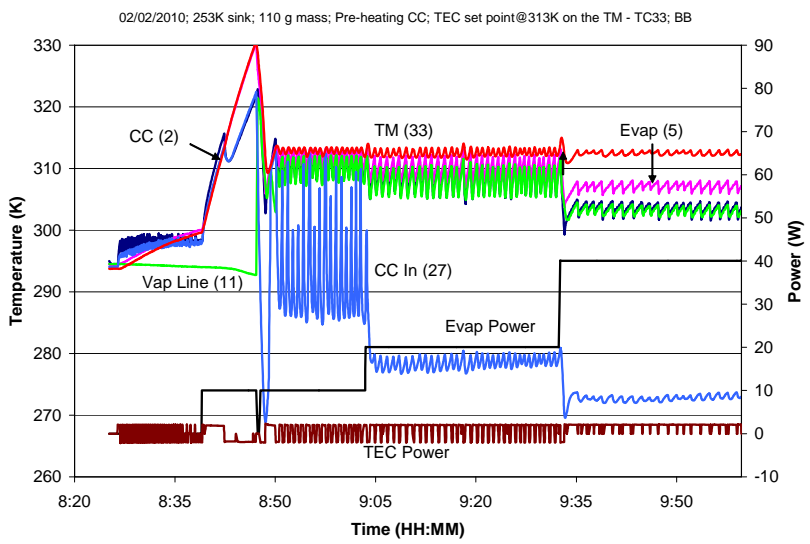

Figure 18. Temperature Profiles for Startup with Thermal Mass Controlled at 313K (117g/TEC/on-off)

350-gram Thermal Mass with PID and On-Off Control Schemes - The effect of the thermal mass on the loop operation is presented next. The power ramp-up tests were conducted with the 350-gram thermal mass attached to the evaporator. Figure 19 shows the temperature profiles for the test where the control temperature sensor was placed on the thermal mass (TC\#33), and the TEC was controlled via a PID scheme. The thermal mass temperature could be controlled at its set point of $313 \mathrm{~K}$ over a power range of $10 \mathrm{~W}$ to $80 \mathrm{~W}$ with no noticeable oscillations except at the very beginning of the startup. At $100 \mathrm{~W}$, the thermal mass temperature was higher than its set point of 313K because the natural operating temperature of the reservoir was higher than that required to keep the thermal mass at 313K. When the heat load was decreased to $30 \mathrm{~W}$, the thermal mass was kept at 313K again. As the heat load was lowered to $10 \mathrm{~W}$, no temperature oscillations were seen. Thus, compared to the temperature profiles shown in Figure 11, the loop ran more stably with the 350-gram thermal mass than with the 117-gram thermal mass.

Figure 20 shows the temperature profiles during the startup transient. When $10 \mathrm{~W}$ was applied to the thermal mass, the TEC was turned on. The reservoir temperature continued to rise until the thermal mass reached $313 \mathrm{~K}$ and the TEC power was turned off. While the thermal mass temperature continued to rise, the reservoir temperature 
continued to decrease. The loop started when the thermal mass was at $318 \mathrm{~K}$ and the reservoir at $313 \mathrm{~K}$ (5K superheat). A slug of cold liquid was injected into the reservoir following the startup, causing the reservoir temperature to drop, which also brought the thermal mass temperature below 313K. The TEC was turned on. The fast rise of the reservoir temperature caused the loop to shut down. But the loop started again quickly. From then on, the loop operated stably without repeated startup and shutdown cycles as seen in Figure 8.

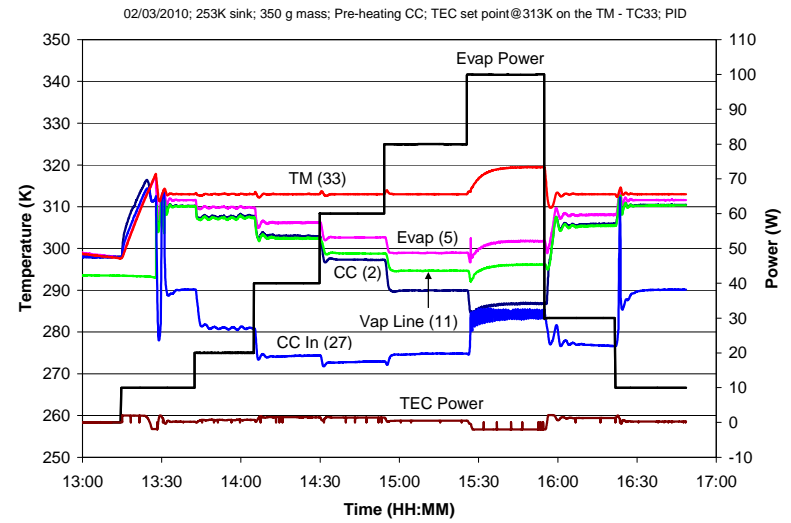

Figure 19. Temperature Profiles for Test with Thermal Mass Controlled at 313K (350g/TEC/PID))

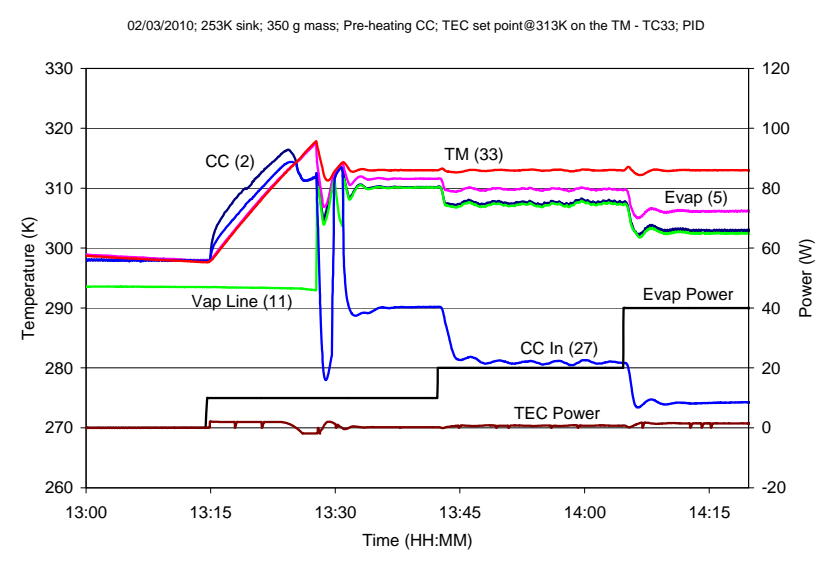

Figure 20. Temperature Profiles for Startup with Thermal Mass Controlled at 313K (350g/TEC/PID)

Figure 21 shows the temperature profiles for a test that was similar to those shown in Figure 19 except that the TEC was controlled via the on/off scheme. The thermal mass temperature was controlled at its set point of 313K over the power range between $10 \mathrm{~W}$ and $80 \mathrm{~W}$. At $100 \mathrm{~W}$, the thermal mass temperature exceeded $313 \mathrm{~K}$ because the reservoir was running at its natural operating temperature which was higher than that required to maintain the thermal mass at 313K. At 120W, the reservoir's natural operating temperature was even higher, which was expected, and the thermal mass temperature rose to $328 \mathrm{~K}$. When the heat load was decreased to $30 \mathrm{~W}$, the reservoir temperature dropped and the thermal mass temperature was maintained at 313K again. During the startup with 10W, large temperature oscillations were seen on the reservoir, evaporator, vapor line, and especially on the liquid line as seen in Figure 22. The temperature oscillations appeared again at the end of the test with 10W heat load. The loop ran close to be shut down occasionally. The temperature oscillations were caused by the on and off cycles of the TEC power.

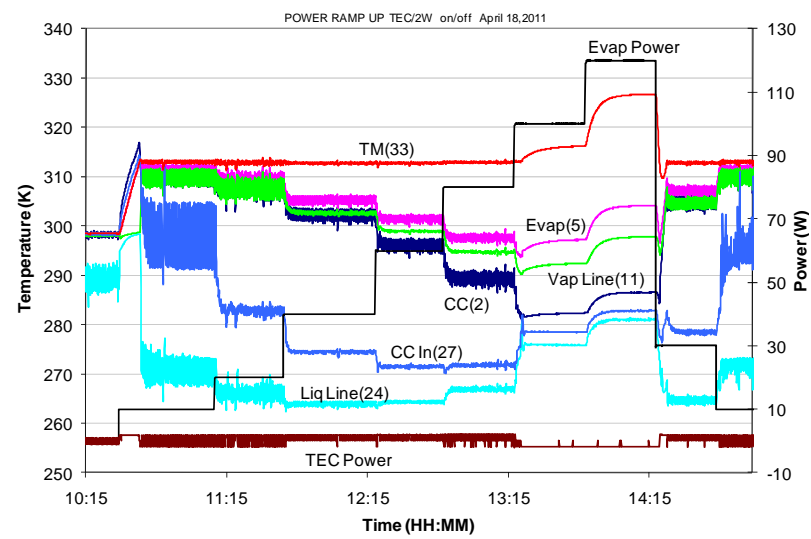

Figure 21. Temperature Profiles for Test with Thermal Mass Controlled at 313K (350g/TEC/on-off)

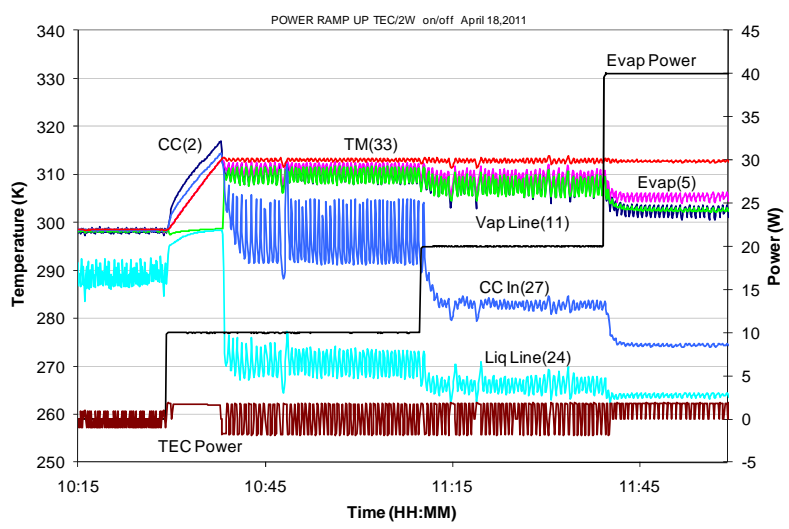

Figure 22. Temperature Profiles for Startup with Thermal Mass Controlled at 313K (350g/TEC/on-off)

The LHP operating temperature is governed by the saturation temperature of its reservoir. When the control temperature sensor is placed on the thermal mass, it is expected that the reservoir will respond to the change more slowly than when the control sensor is placed on the reservoir itself. This could result in larger temperature oscillations during fast transients. If the power profile is know in advance, however, it is possible to place the 
control temperature sensor on the reservoir and still maintain the heat source at the desired set point. This can be accomplished by adjusting the reservoir set point temperature as a function of the heat load based on the known thermal resistance between the thermal mass and the reservoir. Such tests were performed under this test program.

Figure 23 shows the temperature profiles when the control temperature sensor was placed on the reservoir and the reservoir set point was varied with the heat load applied to the 117- gram thermal mass. The reservoir set point as a function of the heat load was taken from the experimental data shown in Figure 7 and the TEC was controlled via the PID scheme. Using this method, the thermal mass temperature was maintained fairly constant at 313K for powers between $10 \mathrm{~W}$ and $80 \mathrm{~W}$, and temperature oscillation seen in Figure 11 disappeared. A similar test was performed with the 350-gram thermal mass attached to the evaporator. The reservoir set point temperature as a function of the heat load was taken from experimental data shown in Figure 19. The temperature profiles are shown in Figure 24. Again, the thermal mass temperature was maintained fairly constant for powers between $10 \mathrm{~W}$ and $80 \mathrm{~W}$, and temperature oscillation at 10W during the start-up transient disappeared.

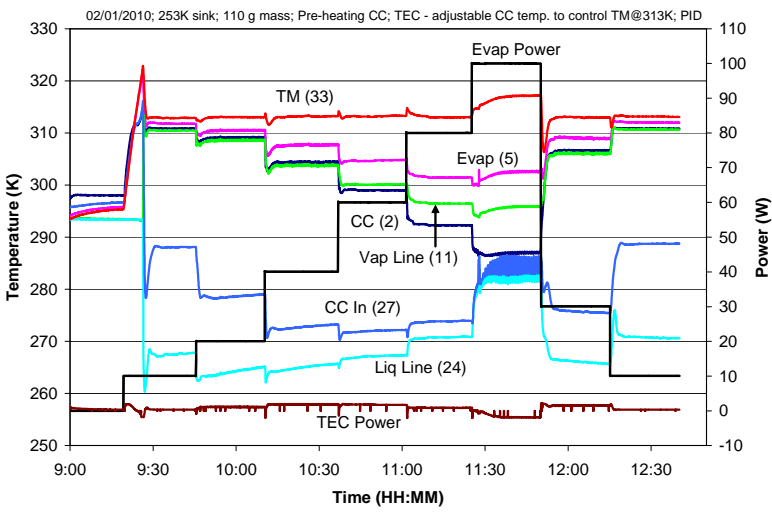

Figure 23. Varying CC Temperature to Maintain Thermal Mass at 313K (117g/TEC/PID)

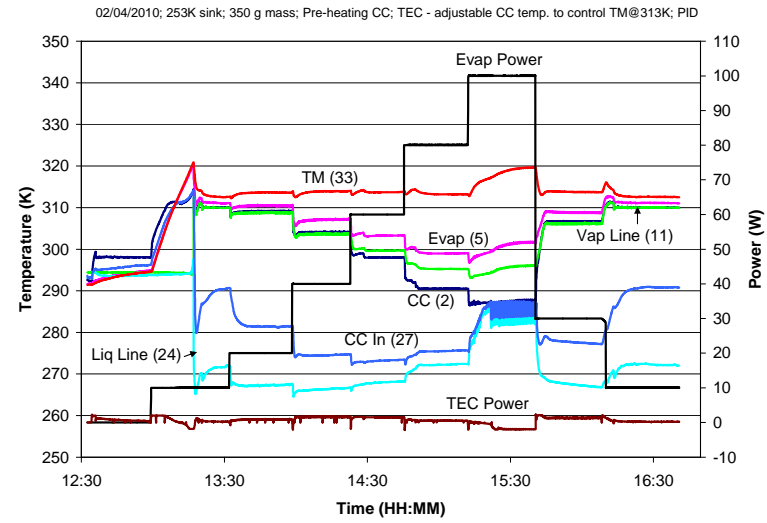

Figure 24. Varying CC Temperature to Maintain Thermal Mass at 313K (350g/TEC/PID)

Power Cycles - The power profile from the heat source is usually not known in advance. To compare the advantages and disadvantages of placing the control temperature sensor on the reservoir versus on the thermal mass, several power cycle tests were performed where the heat load to the thermal mass was changed between $40 \mathrm{~W}$ and $80 \mathrm{~W}$, and between $20 \mathrm{~W}$ and $80 \mathrm{~W}$. When the control temperature sensor was placed on the reservoir, the set point was set at a constant value of 298K. Under this condition, the thermal mass temperature would vary with the heat load. When the temperature sensor was placed on the thermal mass, the set point was set at 313K. Under this condition, the reservoir temperature would change with the heat load. The purpose of these tests was to study the loop's response and the temperature variation of the thermal mass as the heat load changed.

Figure 25 shows the temperature profiles for the test with 350 gram thermal mass and the control temperature was placed on the thermal mass with a set point of 313K. The thermal mass temperature could be maintained at $313 \mathrm{~K}$ at all powers during steady state. Its temperature fell to $310 \mathrm{~K}$ temporarily when the power decreased from $80 \mathrm{~W}$ to $40 \mathrm{~W}$, and to $308 \mathrm{~K}$ when the power decreased from $80 \mathrm{~W}$ to $20 \mathrm{~W}$. When the power dropped from $80 \mathrm{~W}$ to $40 \mathrm{~W}$ or $20 \mathrm{~W}$, the reservoir temperature must be increased to maintain the thermal mass temperature at $313 \mathrm{~K}$. With a maximum heater power of $2 \mathrm{~W}$ to the TEC, the reservoir temperature could not be raised quickly enough. A larger TEC power would alleviate the problem.

Figure 26 shows the temperature profiles for a similar power cycle tests where the control temperature sensor was placed on the reservoir with a set point of $298 \mathrm{~K}$. The same heater power of $2 \mathrm{~W}$ was provided to the TEC, which was controlled via the PID scheme. The thermal mass temperature varied from $305 \mathrm{~K}$ to $308 \mathrm{~K}$ and to $320 \mathrm{~K}$ when the heat load changed from $20 \mathrm{~W}$ to $40 \mathrm{~W}$ and to $80 \mathrm{~W}$, respectively. These temperature variations were due to the heat transfer requirement at different powers. The temperature increased and decreased smoothly during the power transients. 


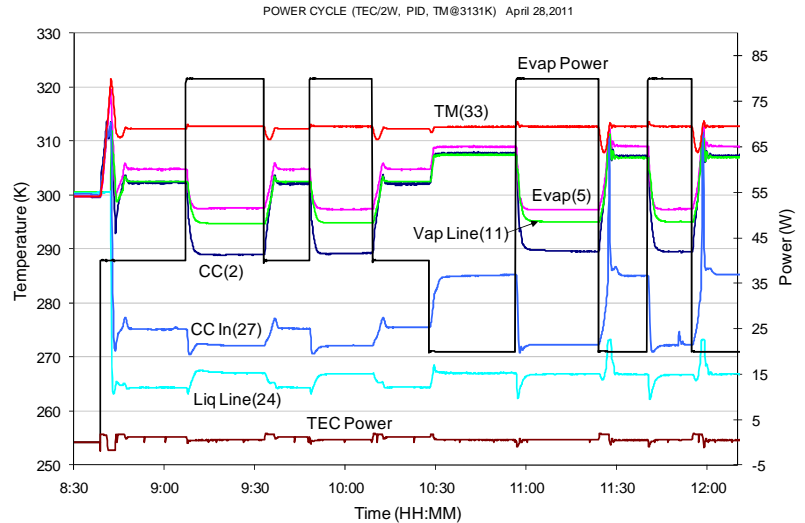

Figure 25. Temperature Profiles for Power Cycle Test with Thermal Mass Controlled at 313K (350g/TEC/PID)

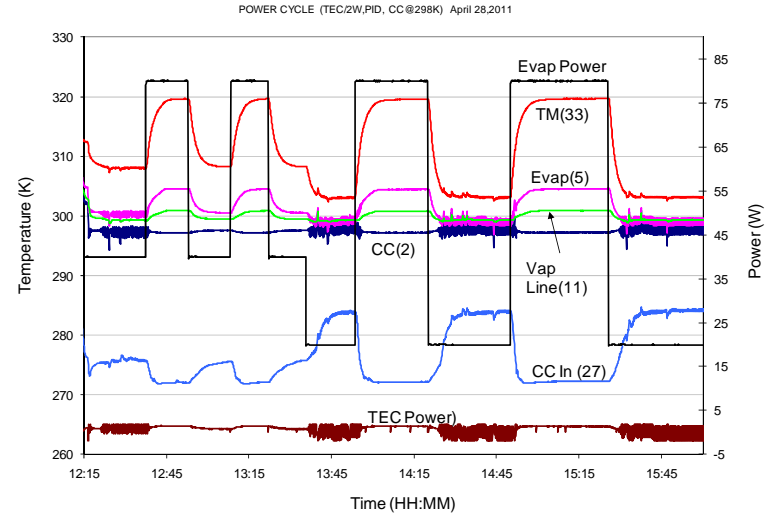

Figure 26. Temperature Profiles for Power Cycle Test with CC Controlled at 298K (350g/TEC/PID)

The same power cycle tests were repeated with the same conditions except that the TEC was controlled via the on/off scheme. The results are shown in Figure 27 and 28. The thermal mass temperatures at 20W, 40W and 80W shown in Figure 27 were the same as those shown in Figure 25 except for larger temperature oscillations resulting from the on/off events of the TEC control. The same conclusion can be drawn for the power cycle test where the control temperature sensor was placed on the reservoir with a set point of $298 \mathrm{~K}$ by comparing the temperature profiles shown in Figure 28 and Figure 26.

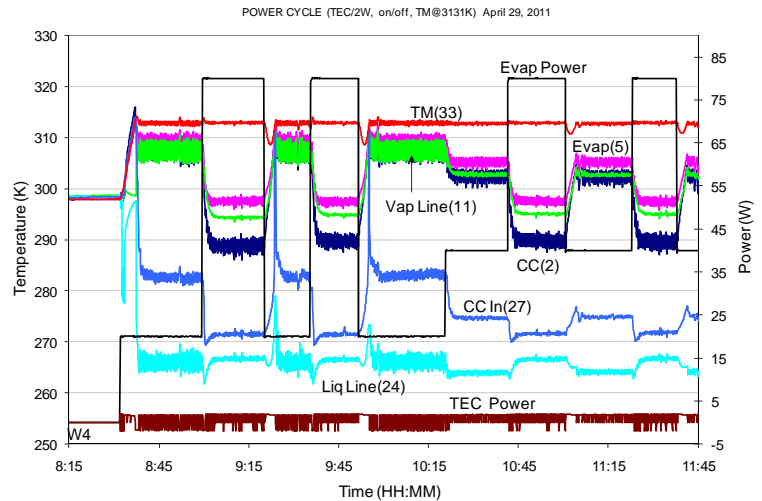

Figure 27. Temperature Profiles for Power Cycle Test with Thermal Mass Controlled at 313K (350g/TEC/On-Off)

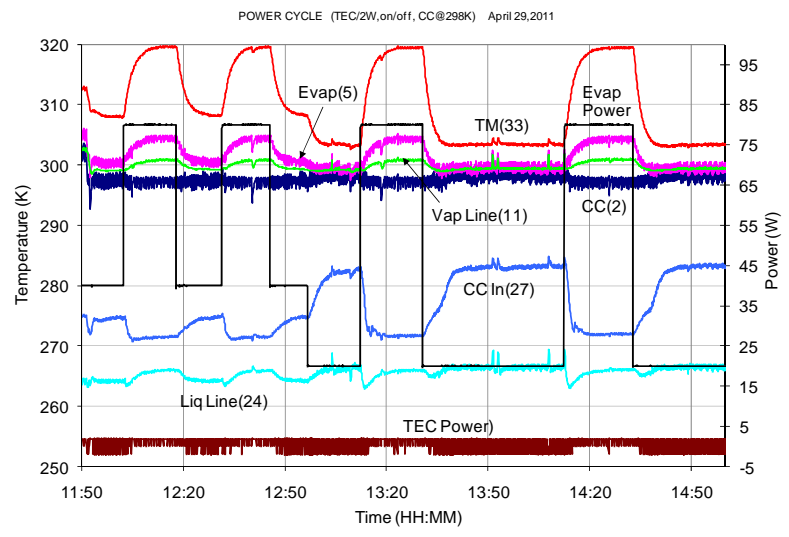

Figure 28. Temperature Profiles for Power Cycle Test with CC Controlled at 298K (350g/TEC/On-Off)

\section{Summary and Discussions}

This test program was carried out to investigate the feasibility of using the heat source temperature for feedback control of the LHP operation. In this method, the control temperature sensor was placed on the heat source and this temperature was used to alter the saturation temperature of the reservoir, which was cold biased and heated by a control heater. As the heat output from the heat source changed, the reservoir temperature must vary in order to maintain the heat source at the desired set point temperature. Test results show that this method is feasible and the heat source can be maintained at the desired set point over a large range of heat loads. The main issue with this method is the LHP operation at low powers where interactions between the reservoir and the heat source can result in large temperature oscillations. This is particularly true for the loop startup, which is usually a low power operation. 
The above results show that it is feasible and may be even advantageous to place the control temperature sensor on the heat source rather than on the reservoir when a TEC is used as the control heater. Because a TEC is capable of providing both heating and cooling to the reservoir, any fast transient temperature change can be better mitigated. Unfortunately, the same cannot be said when an electric heater is used as the reservoir control heater. Tests performed under this test program using an electric heater showed that the fast temperature transients could persist and could even be amplified because the electric heater had no cooling capability. As an example, Figure 29 shows the temperature profiles of a power ramp-up test where the control sensor was place on the 350-gram thermal mass with a set point of $313 \mathrm{~K}$ and an electric heater was used to regulate the reservoir temperature using the PID scheme. This test was similar to that shown in Figure 19. In this test, the loop went through repeated startup and shutdown cycles at $10 \mathrm{~W}$ and $20 \mathrm{~W}$, and large temperature oscillations were seen on the loop components and the thermal mass. Figure 30 shows more details of the temperature oscillations during the startup transient. The loop began it normal operation at $40 \mathrm{~W}$ but still went through some temperature oscillations until the power was increased to $80 \mathrm{~W}$. When the power was decreased to $30 \mathrm{~W}$, large temperature oscillations re-appeared. When the power was further decreased to $10 \mathrm{~W}$, the loop resumed its startup and shutdown cycles. The same test with an electric heater and the on/off control scheme yielded similar results. Thus, more sophisticated control schemes are needed in order to gain stable loop operation and good temperature control of the heat source. Results of the tests with an electric heater for reservoir temperature regulation under this test program will be published in another paper.

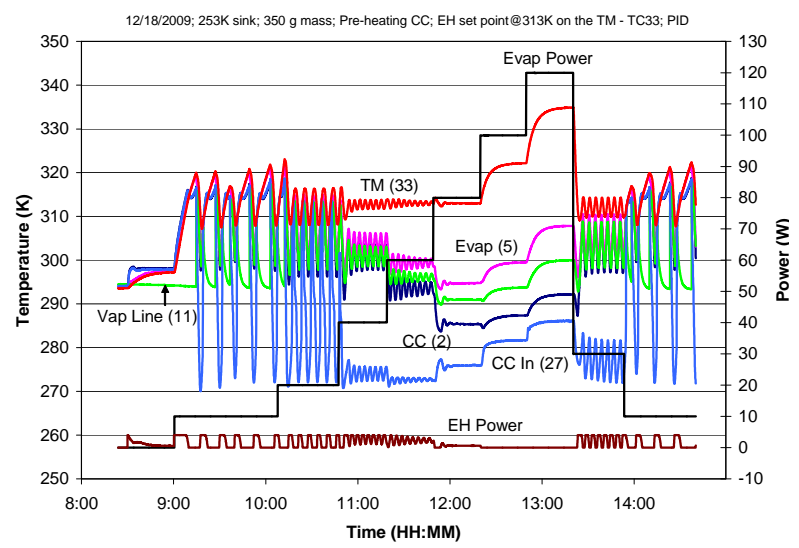

Figure 29. Temperature Profiles for Test with Thermal Mass Controlled at 313K (350g/EH/PID)

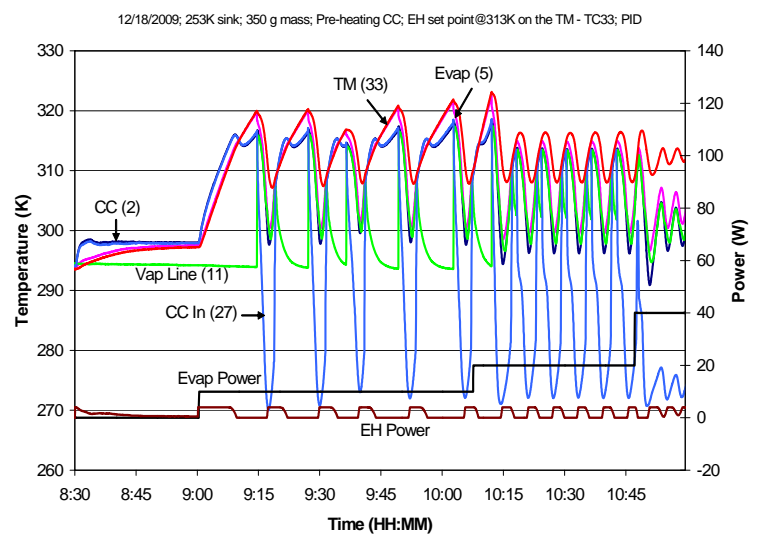

Figure 30. Temperature Profiles for Startup with Thermal Mass Controlled at 313K (350g/EH/PID)

\section{Conclusion}

It is feasible to use the heat source temperature for feedback control of the LHP operation. By placing the control temperature sensor on the heat source, and attaching a control heater to the reservoir to regulate its saturation temperature in accordance with the heat load, the heat source can be maintained within a tight temperature range. A potential drawback of this method is that temperature oscillation can occur at low powers where the LHP may display repeated startup and shutdown cycles. Using a TEC as the reservoir control heater, this problem can be avoided or alleviated. Results of the power cycle tests show that it may be advantageous to place the control temperature sensor on the heat source itself when a TEC is used as the reservoir control heater. No sophisticated control algorithm is needed for the TEC. However, a bipolar power supplied is required so that the TEC can automatically change its operation between the heating and cooling modes as required. The use of a TEC to control the reservoir temperature for LHP operation has been tested in ground tests and demonstrated excellent performance. However, such application has not been demonstrated in space.

\section{References}

1. Maidanik, Y., and Fershtater, Y., “Theoretical Basis and Classification of Loop Heat Pipes and Capillary Pumped Loops,” $10^{\text {th }}$ International Heat Pipe Conference, Stuttgart, Germany, 1997.

2. Ku, J., “Operating Characteristics of Loop Heat Pipes,” SAE Paper No. 1999-01-2007, 29 ${ }^{\text {th }}$ International Conference on Environmental Systems, Denver, Colorado, July 12-15, 1999.

12

American Institute of Aeronautics and Astronautics 
3. Baker, C., Butler, D., Ku, J., and Grob, E., "Acceptance Thermal Vacuum Tests of the GLAS Flight Loop Heat Pipe Systems,” Space Technology and Applications International Forum -2001, Albuquerque, New Mexico, February 11-14, 2001.

4. Baker, C and Grob, E., "System Accommodation of Propylene Loop Heat Pipes for the Geoscience Laser Altimeter System (GLAS) Instrument,” SAE Paper No. 2001-01-2263, 31 $1^{\text {st }}$ International Conference on Environmental Systems, Orlando, Florida, July 9-12, 2001.

5. Grob, E., Baker, C., and McCarthy, T., "Geoscience Laser Altimeter System (GLAS) Loop Heat Pipe: An Eventful first Year On-Orbit”, Paper No. 2004-01-2558, 34 ${ }^{\text {th }}$ International Conference on Environmental Systems, Colorado Springs, Colorado, July 19-22, 2004.

6. Ottenstein, L., Ku, J., and Feenan, D., "Thermal Vacuum Testing of a Novel Loop Heat Pipe Design for the Swift BAT Instrument," Space Technology and Applications International Forum -2003, Albuquerque, New Mexico, February 2-6, 2003.

7. Choi, M., "Swift BAT Loop Heat Pipe Thermal System Characteristics and Ground/Flight Operation Procedure,” Paper No. AIAA 2003-6077, $1^{\text {st }}$ International Energy Conversion Engineering Conference, Portsmouth, Virginia, August 17-21, 2003.

8. Choi, M., "Thermal Vacuum/Balance Test Results of Swift BAT with Loop Heat Pipe Thermal System”, AIAA Paper No. 20045683, $2^{\text {nd }}$ International Energy Conversion Engineering Conference, Providence, Rhode Island, August 16-19, 2004.

9. Choi, M., “Thermal Assessment of Swift BAT Instrument Thermal Control System In Flight”, Paper No. 2005-01-3037, 35 International Conference on Environmental Systems, Rome, Italy, July 11-14, 2005.

10. Rodriguez, J. I., Na-Nakornpanom, A., Rivera, J., Mireles, V. and Tseng, H., "On-Orbit Thermal Performance of the TES Instrument - Three Years in Space,” SAE Paper No. 2008-01-2118, 38 ${ }^{\text {th }}$ International Conference on Environmental Systems, San Francisco, California June 30 - July 2, 2008.

11. Nikitkin, M. and Wolf, D., "Development of LHP with Low Control Power," Paper No. 2007-01-3237, 37 ${ }^{\text {th }}$ International Conference on Environmental Systems, Chicago, Illinois, July 9-12, 2007.

12. Nikitkin, M. N., Kotlyarov, E. Y. and Serov, G. P., "Basics of Loop Heat Pipe Temperature Control”, Paper No. 1999-01-2012, $29^{\text {th }}$ International Conference on Environmental Systems, Denver, Colorado, July 12-15, 1999.

13. Ku, J., "Methods of Controlling the Loop Heat Pipe Operating Temperature," SAE Paper No. 2008-01-1998, 38 ${ }^{\text {th }}$ International Conference on Environmental Systems, San Francisco, California, June 30 - July 2, 2008.

14. Ku, J., Jeong, S., and Butler, D., ’Testing of a Miniature Loop Heat Pipe with Thermal Electrical Cooler for Temperature Control," SAE Paper No. 2004-01-2505, $34^{\text {th }}$ International Conference on Environmental Systems, Colorado Springs, Colorado, July 19-22, 2004.

15. Ku, J., Ottenstein, L., and Birur, G., "Thermal Performance of a Multi-Evaporator Loop Heat Pipe with Thermal Masses and Thermoelectric Coolers”, $13^{\text {th }}$ International Heat Pipe Conference, Shanghai, China, September 21-25, 2004.

16. Ku, J. and Nagano, H., ”Using Thermoelectric Converters for Loop Heat Pipe Operating Temperature Control,” AIAA Paper No. AIAA-2006-4057, $4^{\text {th }}$ Intersociety Energy Conversion Engineering Conference, San Diego, California, June 2629, 2006.

17. Ku, J. and Nagano, H., “Loop Heat Pipe Operation with Thermoelectric Converters and Coupling Blocks,” AIAA Paper No. AIAA-2007-4713, $5^{\text {th }}$ Intersociety Energy Conversion Engineering Conference, St. Louis, Missouri, June 25-27, 2007. 